\title{
Isolation, identification and characterization of endophytic fungi of Bambusa oldhamii munro applied as antagonists to Pyricularia oryzae ${ }^{1}$
}

\author{
Andreia Alves da Costa Silveira ${ }^{2}{ }^{*} \mathbb{D}$, Leila Garcês Araújo ${ }^{3}$, Marta Cristina Corsi de Fillipi ${ }^{4}$, Sérgio Tadeu Sibov ${ }^{3}$
}

10.1590/0034-737X202067040007

\begin{abstract}
Endophytic fungi, in addition to improving plant development, may produce antimicrobial substances that can inhibit pathogens. The objective of this study was to isolate and characterize endophytic fungi of Bambusa oldhamii and evaluate in vitro antagonism to Pyricularia oryzae. Fungal isolates of $B$. oldhamii shoots were purified and identified by nuclear ribosomal DNA (nrDNA) including internal transcribed spacer regions (ITS1 and ITS4). These isolates were then confirmed by phylogenetic analysis of the ITS1 and ITS2 sequences and morphological analysis. The isolates were evaluated in in vitro experiments of direct and indirect antagonism (volatile production). Five fungal isolates were identified and named as follows: isolate 27 (Arthrinium sp.); isolate 29 (Acrocalymma sp.); isolate 122 (Botryobambusa fusicoccum); isolate 711 (Phoma sp.) and isolate 712 (Phoma sp.). We found that the area of the $P$. oryzae colony was reduced by more than $80 \%$ by all endophytic isolates in this study, with emphasis on isolate 122 , with a $96 \%$ reduction in area of the $P$. oryzae. These results were considered promising and will serve as a foundation for future studies on induction of resistance to $P$. oryzae.
\end{abstract}

Keywords: antagonism; antimicrobial activity; bamboo; bambusicolous fungi.

\section{INTRODUCTION}

Endophytic fungi are microorganisms that live within plants for at least a part of their life cycle without causing any visible manifestation of disease. This relationship benefits the host in several ways, protecting it from biotic and abiotic stress (Selim et al. 2012). This relationship includes secretions of substances by endophyte, which are biologically active metabolites which promote antagonistic action against phytopathogens (Zhang et al. 2006; Sudha et al. 2016).

Bambusicolous fungi (formerly fungorum bambusicolorum) are species that have association with bamboo species (Dai et al. 2017). This group is estimated to include more than 1,450 species in approximately 115 genera around the world. They include ascomycetes, basiomycetes, coleomycetes, hyphomycetes and anamorphic fungi (Shukla et al. 2016; Dai et al. 2017). These fungi, are important because of the compounds they produce, such as metabolites with antioxidant, antimicrobial and antitumor properties (Oyetayo et al. 2009). Therefore, research involving the identification and characterization of species associated with bamboo is necessary in order to use these compounds in the biocontrol of pathogens in cultivated plants in the future (Oyetayo et al. 2009; Ebada et al. 2011; Li et al. 2012).

Currently, there is high demand for biological agents for disease control in various crops. Excessive use of pesticides for pathogen control in agriculture generates a series of environmental problems such as soil and groundwater contamination by heavy metals ( $\mathrm{Lu}$ et al. 2015). Rice blast is the major disease in rice cultivation, caused by the fungus Pyricularia oryzae B. C. Couch [anamorph - Magnaporthe oryzae Cavara]. Under

\footnotetext{
Submitted on September $5^{\text {th }}, 2019$ and accepted on June $4^{\text {th }}, 2020$

${ }^{1}$ This work is part of the first author's doctoral thesis.

${ }^{2}$ Universidade Federal de Goiás, Escola de Agronomia, Goiânia, Goiás, Brazil. andreiaac2@gmail.com

${ }^{3}$ Universidade Federal de Goiás, Instituto de Ciências Biológicas, Goiânia, Goiás, Brazil. leilagarcesaraujo@gmail.com; stsibov@gmail.com

${ }^{4}$ Empresa Brasileira de Pesquisa Agropecuária, Santo Antônio de Goiás, Goiás, Brazil. macrisfilippi@gmail.com

*Corresponding author: andreiaac2@gmail.com
} 
favorable conditions, rice blast can cause crop losses of up to $100 \%$ (Prabhu et al. 1992; Prabhu \& Filippi 2001; Prabhu et al. 2009). For disease control, in addition to the use of fungicides, integrated management by means of farming practices is also necessary (Prabhu \& Filippi 2001).

$P$. oryzae has a cell wall composed of melanin, which is important for the mechanism of pathogen infection, which involves the formation and peg penetration of the appressorium. Melanin plays a structural part in strengthening the appressorium and forms an impermeable layer to prevent leakage of osmolytes, which generate the substantial internal turgor (Wilson \& Talbot 2009). Thus, the loss or blockade of melanin in the colony also implies the loss of pathogenicity (Yan \& Talbot 2016; Oses-Ruiz et al. 2017). Thus, the development of biological control techniques that provide blockade of melanin in P. oryzae colonies could provide improvements in rice production. Research involving antagonist relations between endophytes and pathogens is necessary for future search for novel natural products (Nisa et al. 2015), as well as the identification of bioactive compounds that could be used in research involving induction of resistance in plants (Busby et al. 2016).

When it comes to interactions involving plants and microorganisms, fungal endophytes are involved in multiple balanced antagonisms. In planta, endophytic fungi must deal with multiple organismal interactions. This relationship involves anti-fungal metabolites produced by endophytic fungi, which have the function of maintaining balances of antagonisms with microbial competitors, resulting in a compatible multipartite symbiosis (Schulz et al. 2015). Therefore, research involving identification of endophytic fungi and their antagonisms between $P$. oryzae are necessary in order to develop natural products in the future that may be inhibitors of pathogen growth under natural conditions, or even use these endophytes as growth resistance inducers. Thus, the objective of this study was to identify and morphologically characterize endophytic fungi of Bambusa oldhamii Munro and to evaluate possible antagonism to $P$. oryzae, for use in future studies on resistance and plant growth promotion.

\section{MATERIALS AND METHODS}

\section{Isolation of endophytic fungi}

Secondary shoots of B. oldhamii measuring 55 - 60 mm were collected in March 2016 at the Bamboo Collection of the Federal University of Goiás (Universidade Federal de Goiás), located in Goiânia, Goiás state, Brazil. The shoots were sectioned into $50 \mathrm{~mm}$ fragments, surface washed with neutral detergent solution $(50 \mu \mathrm{L}$ per $100 \mathrm{~mL}$ of water) and, after triple washing, immersed in sodium hypochlorite solution $(0.0025 \%$ active chlorine $)$ and stored at $5{ }^{\circ} \mathrm{C}$ for $24 \mathrm{~h}$. In a laminar flow chamber, asepsis was performed with Tween $80^{\circledR}$ solution $(50 \mu \mathrm{L}$ per $100 \mathrm{~mL})$ for $10 \mathrm{~min}, 70 \%$ ethanol for $5 \mathrm{~min}$ and sodium hypochlorite ( $2.5 \%$ active chlorine) for $15 \mathrm{~min}$, followed by triple washing in deionized and autoclaved water after each step. After asepsis, the shoots were immersed in a 5\% solution of Plant Preservative Mixture ${ }^{\circledR}$ (PPM) biocide for $24 \mathrm{~h}$. Then, the samples were cut into $30 \mathrm{~mm}$ fragments and transferred to test tubes containing MS medium (Murashige \& Skoog, 1962) supplemented with 30\% sucrose, $0.45 \mu \mathrm{M}$ thidiazuron (TDZ) (Lin et al. 2007), 0.2\% $\mathrm{PPM}^{\circledR}$ and $103.5 \mu \mathrm{M}$ kanamycin. The test tubes containing the shoots and culture medium remained in the dark for 15 days and then were incubated for 15 days in the growth room under cold white light with light intensity of $35 \mu \mathrm{mol}$ $\mathrm{m}^{-2} \mathrm{~s}^{-1}$ and a photoperiod of $16 \mathrm{~h}$ light.

After 30 days, the fungal colonies grown in the ten test tubes were transferred twice consecutively to Petri dishes containing potato dextrose agar (PDA) medium for purification of the colonies. For this, the mycelium suspension was used. This suspension was spread on Petri dishes (containing $30 \mathrm{ml}$ of PDA medium) with the aid of a glass stick. The color, texture and growth form of the mycelium were observed for purification, as well as the morphological characteristics in microscopic, in order to confirm the purification. In all, five distinct colonies were observed, and the dishes were stored in a growth room at $28 \pm 1{ }^{\circ} \mathrm{C}$ with a photoperiod of $12 \mathrm{~h}$ of light.

\section{DNA extraction and isolate identification}

The mycelium was scraped and the DNA was extracted from the fungal isolates (Dellaporta et al. 1983). The extraction quality was measured using a NanoDrop ${ }^{\mathrm{TM}} 2000$ spectrophotometer and, after diluting the DNA to $20 \mathrm{ng} /$ $\mu \mathrm{l}$, the samples were amplified and sequenced by BPI Biotecnologia Pesquisa e Inovação. The DNA samples were amplified using primers for sequences from internal transcribed spacer genomic regions (ITS1 and ITS4) (White et al. 1990; Manter \& Vivanco 2007). The amplified samples were evaluated on $2 \%$ agarose gels, stained with $0.03 \%$ (v/v) UniSafe Dye, visualized under UV light and quantified by fluorometry (Qubit, ThermoFisher). For the sequencing reaction, a BigDye ${ }^{\circ}$ Terminator v3.1 and Cycle Sequencing Kit (Applied Biosystems) were used. For the precipitation reaction, ethanol/EDTA/sodium acetate were used, according to the protocol suggested by the manufacturer. Automated capillary electrophoresis sequencing was performed on a ABI3500 Genetic Analyzer (Applied Biosystems).

For molecular identification of the isolates, the resulting sequences were subjected to a BLAST search with the NCBI database (http://www.ncbi.nlm.nih.gov/) and were confirmed by phylogenetic analysis of the ITS1- 
5.8S-ITS2 regions. These methods were combined with morphological analysis for isolates in which conidiogenesis was observed in the culture media (described in the next section) based on dichotomous keys and updated revisions (Barnett \& Hunter 1998; Shukla et al. 2016; Dai et al. 2017). The ITS 1 and 2 sequences were aligned via ClustalW using the software MEGA version 7 (Kumar et al. 2016). The tree was constructed using the Maximum Likelihood method (Nei \& Kumar 2000). Bootstrap analysis $(10,000$ replicates $)$ was used as statistical support. The initial trees were obtained by applying the Neighbor-Join and BioNJ algorithms (Saitou $\&$ Nei 1987). Only sequences published in journals were used, and the sequences resulting from this study were deposited into GenBank.

\section{Morphological characterization of colonies}

A 5-mm mycelial disc of each purified fungal colony was transferred to Petri dishes $(90$ x $90 \mathrm{~mm})$ containing 30 $\mathrm{mL}$ of different culture media to induce different morphologies, radial growth rates, and conidiogenesis. The media used were PDA [potato (200 g); dextrose (20 g); agar (20 g)], CMA [corn Meal (30 g); dextrose (10 g); agar (20 g)], OA [oats (40 g); dextrose (20 g); agar (20 g)]; and TSA [tomato (30 g); sucrose (20 g); agar (20 g)]. The dishes containing the culture media and segments of fungal colonies were sealed with PVC film and incubated in a growth room at $28 \pm 1^{\circ} \mathrm{C}$ with a photoperiod of $12 \mathrm{~h}$ of light.

The growth rate of the isolates (radial growth) was calculated as the mean value obtained with the equation: PRG-CRG/CRG, where PRG refers to the radial growth of the previous evaluation and CRG to the current radial growth. The evaluation was performed every 2 days, and the quantitative data were subjected to analysis of variance and the means were compared by the Tukey test at the $5 \%$ significance level.

The evaluation of colonies, color and the presence or absence of conidiogenesis was performed. In addition, the mycelium of isolates was observed under an optical microscope to characterize the hyphae and conidia. For the microscopic observation of the isolates, slides were prepared with fungal mycelium, $10 \mu \mathrm{L}$ of deionized and distilled water and $1 \mu \mathrm{L}$ of methylene blue at a concentration of $0.1 \%$ to stain hyaline hyphae. Observation was performed using an optical microscope coupled with a digital camera.

\section{Antagonism between endophytic isolates of bamboo and the fungus Pyricularia oryzae}

Mycelial discs of bamboo fungal isolates measuring 7 $\mathrm{mm}$ in diameter were placed in dishes containing $30 \mathrm{~mL}$ of PDA culture medium according to the circle method (Da
Luz, 1990), in which discs of the two isolates are positioned equidistant from the dish edges. The dishes containing only P. oryzae mycelial discs placed in the center of the dish were used as controls. The dishes were incubated $\left(28 \pm 1^{\circ} \mathrm{C}\right.$ with a photoperiod of $12 \mathrm{~h}$ light) until full growth of the control was achieved (10 days). Next, the radial mycelium growth of $P$. oryzae on each dish was calculated (Cattelan 1999).

Mycelial discs measuring $5 \mathrm{~mm}$ in diameter of each endophytic isolate were placed in the center of Petri dishes $(90 \times 90 \mathrm{~mm}$ ) containing $30 \mathrm{~mL}$ of PDA culture medium. $P$. oryzae mycelial discs grown in PDA culture medium were also placed in the same way in another Petri dish. The lids of all Petri dishes were removed, and the bases of all dishes containing endophytic isolates (antagonist) and the pathogen ( $P$. oryzae) were combined, forming an experimental unit. Dishes containing only $P$. oryzae mycelial discs were used as controls. The dishes were incubated $\left(28 \pm 1^{\circ} \mathrm{C}\right.$ with a photoperiod of $12 \mathrm{~h}$ light $)$ until full growth of the control was achieved. Next, the radial mycelium growth of $P$. oryzae on each dish was calculated (Dennis \& Webster 1971; Cattelan 1999).

In both the direct and indirect antagonism experiments, the experimental design was completely randomized, with 7 treatments composed of 7 fungal isolates and 4 replicates. The data were subjected to Box-Cox transformation to meet the assumptions of the analysis of variance, and the means were compared by the Tukey test at the 5\% significance level. The data were analyzed using $\mathrm{R}$ version 3.4.3 (R Core Team 2017).

The percentage of growth inhibition (PGI) in direct and indirect antagonism was calculated according to the equation (ND-ED)/ND x 100 (Shen et al. 2012), where ND refers to the diameter of the negative control, i.e., the $P$. oryzae isolate grown without the interference of any antagonist, and ED refers to the diameter of $P$. oryzae when subjected to the antagonism of a $B$. oldhamii endophytic isolate.

\section{RESULTS}

\section{Morphological characterization}

Morphological analysis of colonies in different culture media revealed several morphotype for isolates. (Table 1 and Figure 1). Isolate 27 showed conidiogenesis and chlamydospores in CMA medium (Figure 2). Morphological analysis of this isolate showed brown conidiogenous cells, aggregated or not, globose or lenticular subglobose, measuring $6.83-10.5 \mu \mathrm{m} \times 2.33$ $6.83 \mu \mathrm{m}$ (width $\mathrm{x}$ length). Hyphae were hyaline, measuring $1.62-0.69 \mu \mathrm{m}$. This isolate showed clustered oblong chlamydospores measuring $2.00-6.93 \mu \mathrm{m} \times 4.02-1.33 \mu \mathrm{m}$ (width $\mathrm{x}$ length). 
Isolate 29 showed conidiogenesis in CMA medium and hyaline, oblong, conidiogenous cells, individual or clustered, measuring $1.62-1.78 \mu \mathrm{m}$ x $1.40-1.71 \mu \mathrm{m}$. The hyphae were thin and hyaline, measuring $1.03-1.61 \mu \mathrm{m}$. Isolate 122 presented chlamydospores in OA culture medium. These presented oblong, black, multinucleate cells measuring $4.02-6.08 \mu \mathrm{m} \times 2.03-3.4 \mu \mathrm{m}$. The hyphae were black, septate, uni- or multinucleate, with diameters of $3.33-6.16 \mu \mathrm{m}$ (Figure 2).

Conidiogenesis of isolate 711 was observed in CMA medium. The conidia were of the pycnidia type (Figure 2), measuring 31.87 - $100 \mu \mathrm{m} \times 81.25$ - $100 \mu \mathrm{m}$ (width x length), and had glabrous, globose, blackish brown ostioles (dimensions $12.5-87.26 \mu \mathrm{m}$ ) and a brown peridium. Hyphae were septate, uni- or multinucleate, with dimensions of 9.3 - $19.7 \mu \mathrm{m}$. The CMA culture medium also favored the formation of chlamydospores in isolate 712 (Phoma sp.). These measured $28.13 \times 25.73 \mu \mathrm{m}$, had a red-brown catenulate peridium, and were glabrous, globose or subglobose, individual or clustered (Figure 2). The hyphae were septate, glabrous, uni- or multinucleate, measuring between $6.5-35.5 \mu \mathrm{m}$.

Table 1: Morphological characteristics of the colonies of the endophytic isolates of Bambusa oldhamii evaluated in different culture media

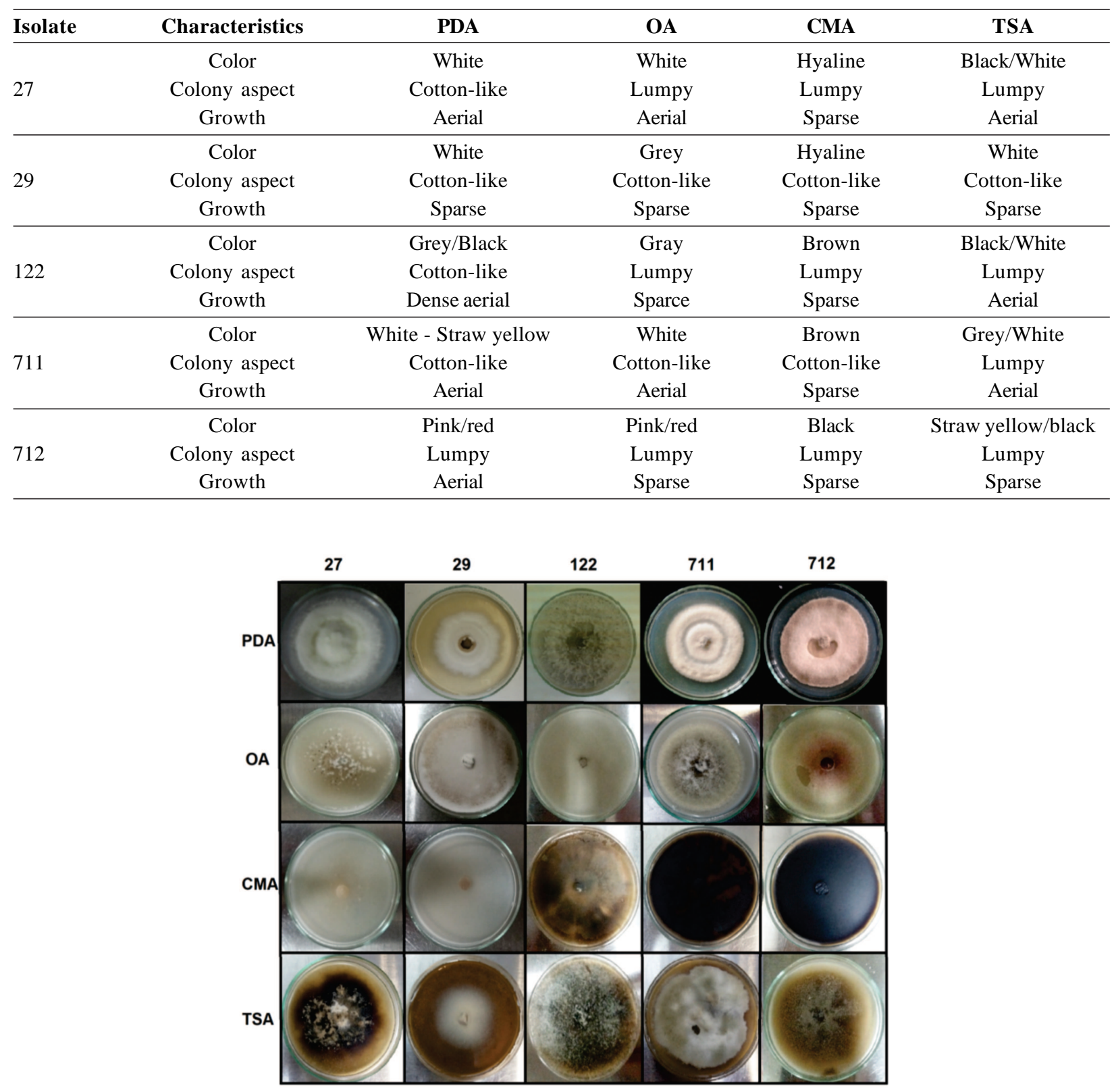

Figure 1: Morphological characterization of the endophytic isolates of B. oldhamii: Arthrinium sp. (27); Acrocalymma sp. (29); Botryobambusa fusicoccum (122); Phoma sp. (711); and Phoma sp. (712); submitted to different culture media: Potato dextrose agar (PDA), oatmeal agar (OA), corn meal agar (CMA), and tomato sucrose agar (TSA). 
Among the different culture media evaluated, the CMA medium significantly favored the growth of isolates 711 and 712. However, no significant difference was observed between this culture medium and the PDA and TSA media regarding colonies of isolate 122 . For isolates 27 and 29, all culture media favored colony growth, with no significant difference among them.

Isolate 122 presented faster growth than the other fungi (Table 2) and achieved full growth in the Petri dish $(90 \times 90$ $\mathrm{mm}$ ) after approximately $48 \mathrm{~h}$ in PDA medium. By contrast, isolate 29 (Acrocalymma sp.) presented the slowest mycelial growth in the culture evaluated media (Table 2).

\section{Molecular identification}

After purification of the mycelium, five isolates were obtained, which were called isolates 27, 29, 122, 711 and 712. Amplification of the ITS1-5.8S-ITS2 region with primers ITS 1 and ITS 4 produced fragments of approximately 580 bp for isolates 27 and $122 ; 510 \mathrm{bp}$ for isolate 29; $500 \mathrm{bp}$ for isolate 711; and $550 \mathrm{bp}$ for isolate 712 .

The ITS sequences obtained from the isolates were analyzed using NCBI BlastN from GenBank. There was
100\% similarity for isolate 27 with Arthrinium marii (accession numbers CBS 200.57 and CPC 18902) and $A$. sacchari (accession number CBS:664.74). Isolate 29 showed 93\% similarity with both Acrocalymma vagum (accession 167) and A. medicaginis (accession CPC 24340). Isolate 122 showed $99 \%$ similarity to Botryobambusa fusicoccum (accession MFLUCC 11 C0657) and 96.55\% similarity to Diploidia rosulata (accession CBS 116470). Isolates 711 and 712 showed $100 \%$ and $99 \%$ similarity to Phoma sp. accessions EA-122 and CB-R-4, respectively.

Analysis of the ITS1-5.8S-ITS2 homologous sequences of each endophytic isolate was conducted, resulting in a phylogenetic tree with four families. The bootstrap percentage of the taxa is shown next to the branches (Figure 3). A separate branch was observed for isolate 29 (Acrocalymma sp.) within its respective taxon, indicating a previously unidentified species of Acrocalymma (Figure 3 ). The ITS1 and ITS2 sequence data of isolates were submitted in GenBank. The accession numbers for the nucleotide sequences were: MN381104 for isolate 27; MN381026 for isolate 29; MN381103 for isolate 122; MN381110 for isolate 711; and MN383185 for isolate 712 .

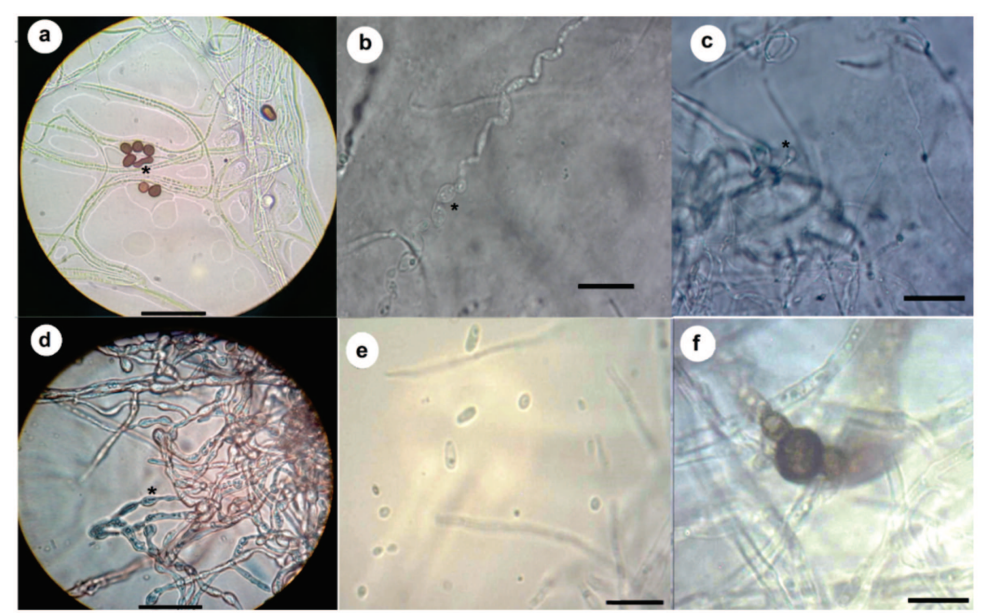

Figure 2: (a) and (b): Isolate 27 (Arthrinium sp.), with emphasis on conidiogenous cells (asterisk) (a), and the chlamydospores (asterisk) (b). (c): conidiogenous cells (asterisk) and hyphae of isolate 29 (Acrocalymma sp.). (d): Chlamydospores (asterisk) of isolate 122 (Botryobambusa fusicoccum); (e) Immature pycnidia of isolate 711 (Phoma sp.). Chlamydospores (f) of isolate 712 (Phoma sp.). Magnification of 40x in (a), (b), (c) and (d), and 100x in (e) and (f). Bar = $10 \mu \mathrm{m}$ in (a), (b), (c) and (d) and $100 \mu \mathrm{m}$ in (e) and (f).

Table 2: Growth rate (\%) per day (mean \pm standard error) of endophytic fungi of Bambusa oldhamii in different culture media: potato dextrose agar (PDA), oatmeal agar (OA), corn meal agar (CMA), and tomato sucrose agar (TSA)

\begin{tabular}{lccccc}
\hline Isolate & Genera & PDA & OA & CMA & TSA \\
\hline 27 & Arthrinium sp. & $22.43 \pm 5.42 \mathrm{bA}$ & $16.68 \pm 1.44 \mathrm{bA}$ & $37.77 \pm 12.2 \mathrm{abA}$ & $20.31 \pm 0.6 \mathrm{bA}$ \\
29 & Acrocalymma sp. & $09.13 \pm 0.59 \mathrm{cA}$ & $10.10 \pm 1.01 \mathrm{bA}$ & $12.02 \pm 2.03 \mathrm{cA}$ & $11.34 \pm 0.07 \mathrm{cA}$ \\
122 & Botryobambusafusicoccum & $49.22 \pm 0.84 \mathrm{aA}$ & $40.50 \pm 0.07 \mathrm{aB}$ & $50.00 \pm 0.01 \mathrm{aA}$ & $50.00 \pm 1.00 \mathrm{aA}$ \\
711 & Phoma sp. & $10.91 \pm 1.30 \mathrm{bcD}$ & $11.33 \pm 1.27 \mathrm{bCD}$ & $38.80 \pm 1.90 \mathrm{abA}$ & $29.76 \pm 1.44 \mathrm{bB}$ \\
712 & Phoma sp. & $12.62 \pm 2.77 \mathrm{bcB}$ & $9.58 \pm 2.40 \mathrm{bB}$ & $36.57 \pm 3.4 \mathrm{abA}$ & $30.41 \pm 3.97 \mathrm{bAB}$ \\
\hline
\end{tabular}

* means followed by the same lowercase letter vertically for analysis of isolates and uppercase letter horizontally for analysis of culture media are not significantly different by the Tukey test at a significance level of $5 \%$. 


\section{Antagonism between endophytic fungi and Pyricularia oryzae}

The mycelial growth of $P$. oryzae was reduced by all isolates in direct antagonism, with emphasis on isolate 122 (B. fusicoccum) (Figure 4), showing a probable competition-type interaction. Similarly to direct antagonism, the volatile components (Figure 5) produced by the isolates under study reduced the area of the $P$. oryzae colony, with reductions of over $80 \%$ (Table 3 and Figure 6), showing a probable inhibition-type interaction. The phenotypes of $P$. oryzae colonies were altered, with loss (total or partial) of the black color (melanin).

\section{DISCUSSION}

Identification of the genera of endophytes of B. oldhamii was successful. Isolate 27 (Arthrinium sp.) belongs to a genus that includes saprophytic species with sexual forms called Apiospora. This species is reported to be a pathogen of bamboo (Martínez-Cano et al. 1992), an endophyte (Ramos et al. 2010) and a lichen (He \& Zhang 2012). Isolate
29 was identified as belonging to the genus Acrocalymma, which includes saprophytic and phytopathogenic species, and includes A. medicaginis (Alcorn \& Irwin 1987). Isolate 122 was identified as belonging to the genus Botryobambusa, whose sole member is the saprophyte $B$. fusicoccum. This species is commonly associated with bamboo, especially of the genus Bambusa (Liu et al. 2012). Isolates 711 and 712 were identified to the genus Phoma, a diverse genus that includes, in addition to growthpromoting microorganisms (Hamayun et al. 2009), phytopathogens, entomopathogens, soil saprophytes, aquatic saprophytes and opportunistic human pathogens (Rai et al. 2009). Endophytic fungi of B. oldhamii were previously reported by Pasqualini et al. (2019), which report that research associated with the discovery of these isolates may increase the current knowledge about the diversity of fungi associated with bamboo. They report the isolation of phylogenetically similar isolates to those found in the present paper, which include: Phoma herbarum, Arthrinium kogelbergense, Arthrinium arundinis, Fusarium graminearum, Wojnowiciella leptocarpi, and Fusarium sp.

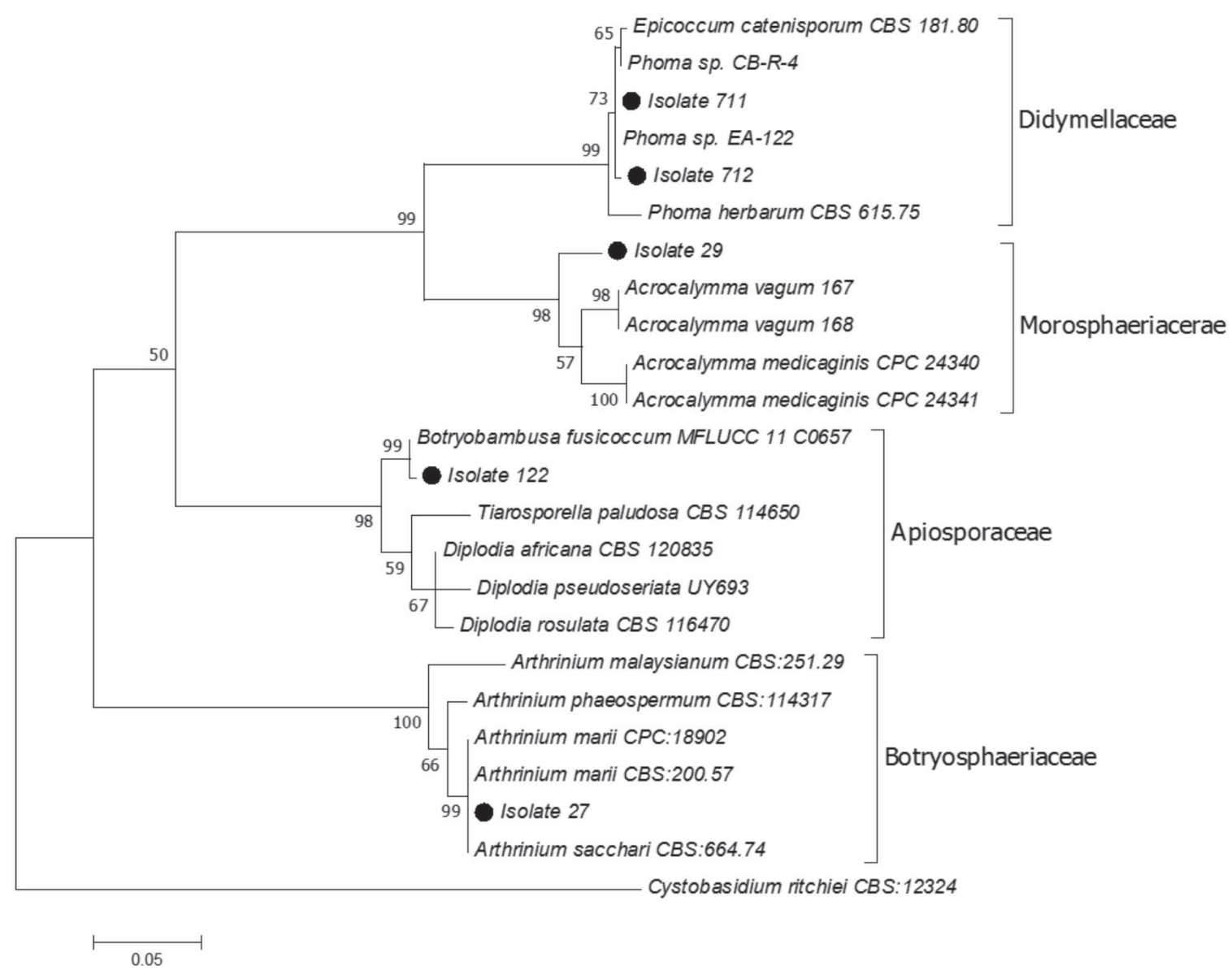

Figure 3: Phylogenetic tree of the ITS 1-5.8S-ITS2 homologous sequence from five endophytic isolates of Bambusa oldhamii (Log $=-2149.26)$ and other nineteen nucleotide sequences. The tree is drawn to scale, with branch lengths measured in the number of substitutions per site. Isolate 712: Phoma sp.; Isolate 711: Phoma sp.; 29: Acrocalymma sp.; 27: Arthrinium sp.; and 122: Bobryobambusa fusicoccum. Cystobasidium ritchiei (CBS:12324) is presented as an outgroup. 
The phylogenetic position of isolates 711 and 712 (Phoma sp.) can still be investigated in the future. In fact, the taxonomic circumscription of the Phoma genus has been complex (Chen et al. 2015; Valenzuela-Lopez et al. 2018). Phoma is ambiguously defined and is subdivided into nine sections based on morphological characters. These sections are classified into four different families, with strains genetically similar to $P$. herbarum belonging to the family Didymellaceae, which includes the genus Epicoccum (Jayasiri 2017). For this reason, Phoma constitutes a polyphyletic group (Gruyter et al. 2009). Despite the efforts of researchers to characterize the group (Chen et al. 2015), there are still gaps in its systematics, both with regard to morphological and molecular characters because many species still remain in nonspecific clades (Aveskamp et al. 2008). Thus, sequencing of additional genomic regions and of isolates similar to isolates 711 and 712 are necessary to better understand the phylogenetic relationships and species boundaries.

The mycelial growth rate and conidiogenesis of the endophytic isolates were influenced by the different culture media evaluated. The nutrient composition of a given culture medium is an important factor that influences the growth rate, as it allows the fungi to grow without restrictions and express phenotypes (Meletiadis et al. 2001). Sharma and Pandey (2010) used different fungal isolates in different culture media and found that the best culture medium for conidiogenesis of the genera Chaetomium, Fusarium, and Penicillium was LCA medium (glucose, $1 \mathrm{~g} ; \mathrm{KH}_{2} \mathrm{PO}_{4}, 1 \mathrm{~g} ; \mathrm{MgSO}_{4} .7 \mathrm{H}_{2} \mathrm{O}, 0.2 \mathrm{~g}$;

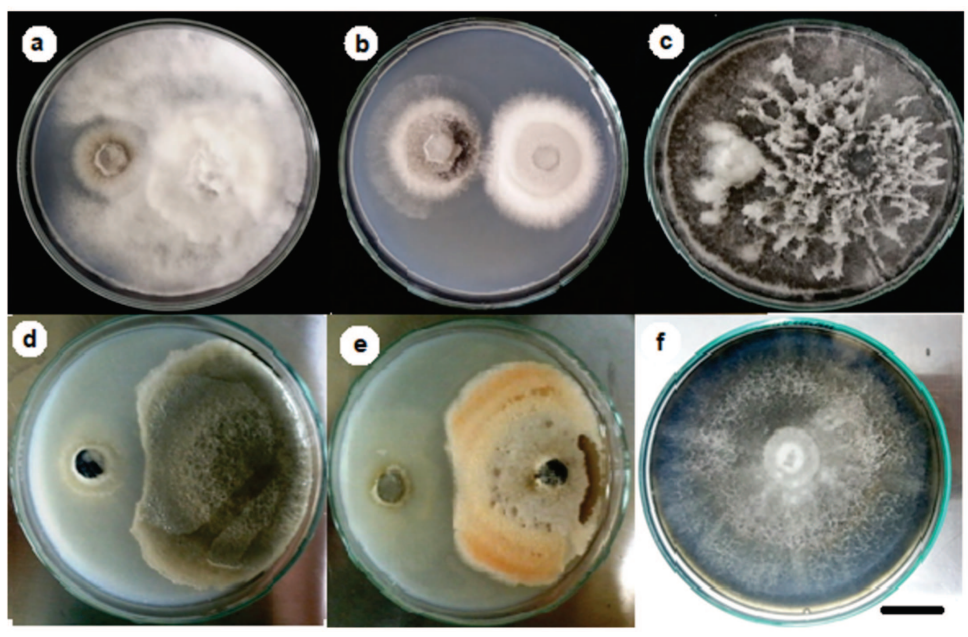

Figure 4: Direct antagonism between endophytic fungi of Bambusa oldhamii (colonies to the right of the dish) and Pyricularia oryzae (colonies to the left of the dish) at ten days of growth (a): 27 (Arthrinium sp.); (b): 29 (Acrocalymma sp.); (c): 122 (Botryobambusa fusicoccum); (d): 711 (Phoma sp.); (e): 712 (Phoma sp.); (f): Control without the antagonist. Bar = $20 \mathrm{~mm}$

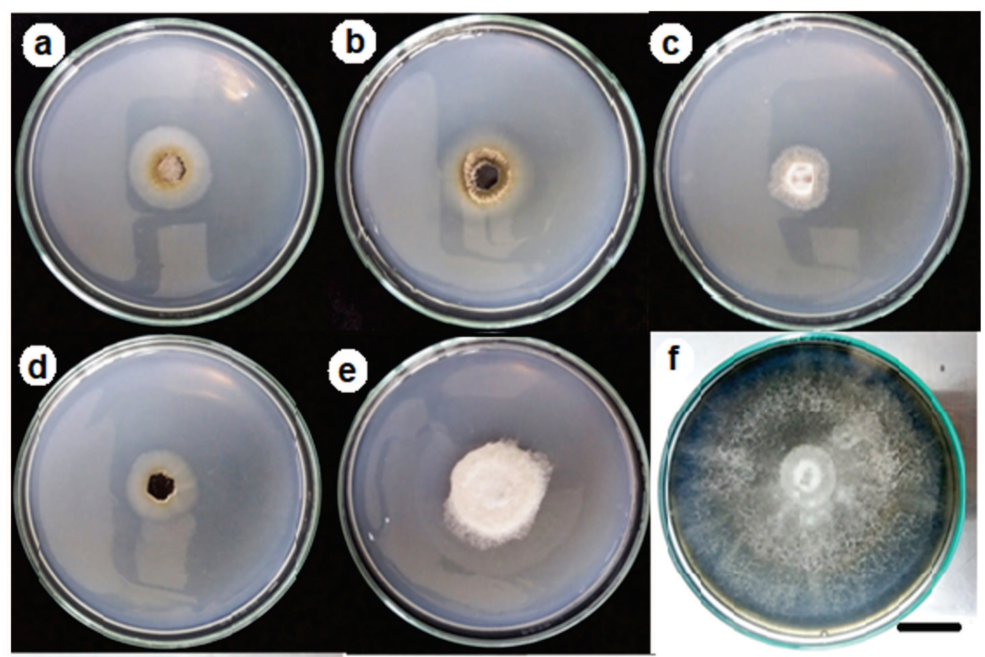

Figure 5: Pyricularia oryzae under indirect antagonism involving endophytic fungi of Bambusa oldhamii (volatile production) at ten days of growth. (a): 27 (Arthrinium sp.); (b): 29 (Acrocalymma sp.); (c): 122 (Botryobambusa fusicoccum); (d): 711 (Phoma sp.); (e): 712 (Phoma sp.); (f): Control without the antagonist. Bar $=20 \mathrm{~mm}$. 
$\mathrm{KCl}, 0.2 \mathrm{~g} ; \mathrm{NaNO}_{3}, 2 \mathrm{~g}$; yeast extract, $0.2 \mathrm{~g}$; agar, $13 \mathrm{~g}$; distilled $\mathrm{H}_{2} \mathrm{O}, 1 \mathrm{~L}$ ) which is a culture medium with reduced amounts of nitrogen and carbohydrates, which may induce conidiogenesis (Miura \& Kudo 1970). In the present study the CMA medium was evaluated, which contains significant amounts of carbohydrates, vitamins and salts. However, not sufficiently rich in amino acids, which are sources of nitrogen (Gernah et al. 2011). Thus, probably the conidiogenesis was influenced by the lack of nitrogen in the culture medium. However, further studies should be performed to substantiate this claim.

Using the direct antagonism assay, we found that the area of the $P$. oryzae colony was reduced by more than $80 \%$ by all endophytic isolates in this study. The interactions involved with biological control include competition, which comprises direct antagonism and is the result of physical contact between the biocontrol organism and the pathogen, in which there is a high degree of selectivity for the pathogen via the mechanism or mechanisms expressed by the biocontrol microorganisms (Harman et al. 2004). These mechanisms include the secretion of enzymes with antimicrobial activity, including PPOs, chitinases, and glucanases (Brzezinska \& Jankiewicz 2012; Naznin et al. 2014). Probably, this metabolite secretion inhibited the production of melanin by $P$. oryzae colonies, when they were submitted to treatments with endophytic isolates. Under natural conditions, $P$. oryzae needs melanin for activation of pathogenicity mechanisms (Carvalho et al. 2015; Oses-Ruiz et al. 2017). Therefore, further in vivo research should be performed to confirm the antagonistic potential of the isolates of the present study.

Using the indirect antagonism assay, we also observed high inhibition of the P. oryzae colony area by all isolates studied (above $80 \%$ ). This result indicates that these endophytes are likely stimulators of defense mechanisms in plants, which can be clarified in future studies on resistance induction (Harman et al. 2004; Silva et al. 2004).

The antagonistic activity of endophytes of bamboo was reported by (Shen et al. 2012), who investigated the antibiosis of endophytes isolated from a Phyllostachys species (Cladosporium sp., Curvularia sp., Penicillium sp., and Didymella sp.) to Pleospora herbarum and Botryotinia fuckeliana, the latter considered a bamboo pathogen (Mohanan 1997). In addition to these, the authors also reported antibiosis of these endophytes with Candida albicans and Staphylococcus aureus, both clinical pathogens.

Table 3: Colony area of Pyricularia oryzae resulting from direct and indirect antagonism with endophytic isolates of Bambusa oldhamii

\begin{tabular}{|c|c|c|c|c|}
\hline \multirow{2}{*}{ Isolate } & \multicolumn{2}{|c|}{ Direct antagonism $(\mathbf{m m})$} & \multicolumn{2}{|c|}{ Indirect antagonism (mm) } \\
\hline & Mean & Standard error & Mean & Standard error \\
\hline Control & $8.100 \mathrm{a}$ & 000.0 & $8.100 \mathrm{a}$ & 000.0 \\
\hline 27 (Arthrinium sp.) & $1025 \mathrm{bc}$ & 241.0 & $0.765 b$ & 042.9 \\
\hline 29 (Acrocalymma sp.) & $1.540 \mathrm{~b}$ & 265.0 & $1.082 b$ & 112.0 \\
\hline 122(Botryobambusa fusicoccum) & $0.320 \mathrm{c}$ & 017.9 & $0.513 b$ & 045.0 \\
\hline 711 (Phoma sp.) & $0.960 \mathrm{bc}$ & 219.0 & $0.599 \mathrm{~b}$ & 043.3 \\
\hline 712 (Phoma sp.) & $1319 b c$ & 272.0 & $1.401 b$ & 133.0 \\
\hline
\end{tabular}

* means that do not share a letter are significantly different by the Tukey test at the $5 \%$ significance level.

(a)

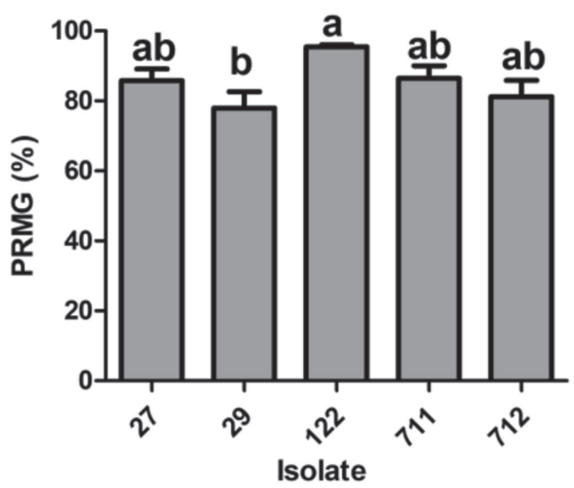

(b)

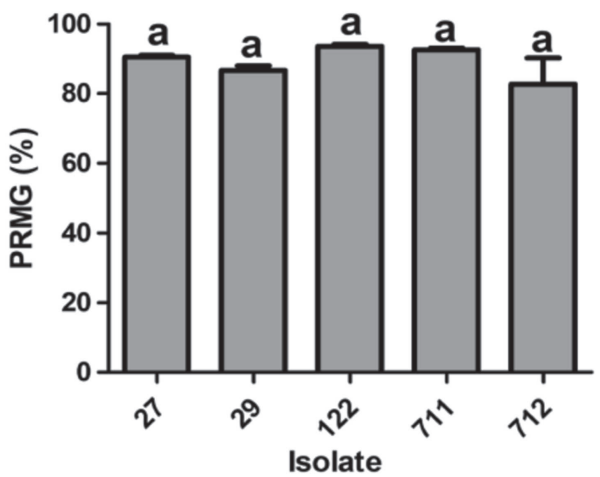

Figure 6: Percentage reduction of mycelial growth (PRMG) of Pyricularia oryzae colonies (mean \pm standard error) by direct (a) and indirect (b) antagonism to endophytic isolates of Bambusa oldhamii. 27 (Arthrinium sp.), 29 (Acrocalymma sp.), 122 (Botryobambusa fusicoccum), 711 (Phoma sp.), and 712 (Phoma sp.). 
No inhibition halo was observed in the direct antagonism assay between $P$. oryzae and isolate 27 (Arthrinium sp.) or isolates 29 (Acrocalymma sp.) and 122 (B. fusicoccum) (Figure 4). However, species of the genus Arthrinium have been reported to have antibacterial (Calvo et al. 1999; Miao et al. 2006), antifungal (Bloor 2008; Ramos et al. 2010) and antiviral (Wang et al. 2015) activity. For this reason, it is suggested that isolate 27 characterized in this study may be the object of future research with other plant species as well as in the interaction with other bacterial pathogens.

\section{CONCLUSIONS}

Five fungal endophytes of $B$. oldhamii were successfully identified and characterized, which were named as: Isolate 27 (Arthrinium sp.); isolate 29 (Acrocalymma sp.); isolate 122 (B. fusicoccum); isolate 711 (Phoma sp.) and isolate 712 (Phoma sp.).

The isolate 122 (B. fusicoccum) presented basic characteristics as an antagonist against $P$. oryzae. The other isolates were also identified as promising for antagonism, including isolate 711 (Phoma sp.) and 712 (Phoma sp.). However, further in vivo studies are required.

\section{CONFLICT OF INTEREST}

The authors declare that there is no conflict of interest.

\section{REFERENCES}

Alcorn JL \& Irwin JAG (1987) Acrocalymma medicaginis gen. et sp.nov. causing root and crown rot of Medicago sativa in Australia. Transations of the British Mycological Society, 88:163-167.

Aveskamp MM, Gruyter J \& Crous PW (2008) Biology and recent developments in the systematics of Phoma, a complex genus of major quarantine significance. Fungal Diversity, 31:01-18.

Barnett HL \& Hunter BB (1998) Illustrated Genera of Imperfect Fungi. $4^{\mathrm{a}}$ ed. Saint Paul, APS Press. 218p.

Bloor S (2008) Arthrinic acid, a novel antifungal polyhydroxyacid from Arthrinium phaeospermum. Jounal of Antibiotics, 61:515517

Brzezinska MS \& Jankiewicz U (2012) Production of antifungal chitinase by Aspergillus niger LOCK 62 and its potential role in the biological control. Current Microbiology, 65:666-672.

Busby PE, Ridout M \& Newcombe G (2016) Fungal endophytes: modifiers of plant disease. Plant Molecular Biology, 90:645655 .

Calvo MA, Agut M, Calvo RM \& Larrondo J (1999) Effect of ultraviolet light irradiation and nitrosoguanidine on viability of 46 strains of Arthrinium and their antibiotic production. Microbios, 98:179-187.

Carvalho JCB, Sousa KCI, Brito DC, Chaibub AA, Luzini AP, Côrtes MVCB, Filippi MCC, Kato L, Vaz BG, Costa HB, Romão W \& Araújo GA (2015) Biocontrol potential of Waitea circinata, an orchid mycorrhizal fungus, against the rice blast fungus. Tropical Plant Pathology, 40:151-159.
Cattelan AJ (1999) Métodos qualitativos para determinação de características bioquímicas e fisiológicas associadas com bactérias promotoras do crescimento vegetal. Londrina, Embrapa soja. 36p. (Documentos, 139).

Chen Q, Jiang JR, Zhang GZ, Cai L \& Crous PW (2015) Resolving the Phoma enigma. Studies in Mycology, 82:137-217.

Dai DQ, Phookamsak R, Wijayawardene NN, Li WJ, Bhat DJ, Xu JC, Taylor JE, Hyde KD \& Chukeatirote E (2017) Bambusicolous fungi. Fungal Diversity, 82:1-105.

Dellaporta SL, Wood J \& Hicks JB (1983) A plant DNA minipreparation: Version II. Plant Molecular Biology Reporter, $1: 19-21$.

Dennis C \& Webster J (1971) Antagonistic properties of speciesgroups of Trichoderma: III. Hyphal interaction. Transations of the British Mycological Society, 57:363-369.

Ebada SS, Schulz B, Wray V, Totzke F, Kubbutat MHG, Müller WEG, Hamacher A, Kassack MU, Lin W \& Proksch P (2011) Arthrinins A-D: Novel diterpenoids and further constituents from the sponge derived fungus Arthrinium sp. Bioorganic and Medicinal Chemistry, 19:4644-4651.

Gernah DI, Ariahu CC \& Ingbian EK (2011) Effects of malting and lactic fermentation on some chemical and functional properties of maize (Zea mays). American Jounal of Food Technology, 6:404-412.

Gruyter J, Aveskamp MM, Woudenberg JHC, Verkley GJM, Groenewald JZ \& Crous PW (2009) Molecular phylogeny of Phoma and allied anamorph genera: Towards a reclassification of the Phoma complex. Mycological Research, 113:508-519.

Hamayun M, Khan SA, Khan AL, Rehman G, Sohn EY, Shah AA, Kim SK, Joo GJ \& Lee IJ (2009) Phoma herbarum as a new gibberellin-producing and plant growth-promoting fungus. Jounal of Microbiology and Biotechnology, 19:1244-1249.

Harman GE, Howell CR, Viterbo A, Chet I \& Lorito M (2004) Trichoderma species -opportunistic, avirulent plant symbionts. Nature Reviews Microbiology, 2:43-56.

He Y \& Zhang Z (2012) Diversity of organism in the Usnea longissima lichen. African Jounal of Microbiology Research, 6:4797-4804

Jayasiri S (2017) Taxonomy and multigene phylogenetic evaluation of novel species in Boeremia and Epicoccum with new records of Ascochyta and Didymella (Didymellaceae). Mycosphere, 8:1080-1101.

Kumar S, Stecher G \& Tamura K (2016) MEGA7: Molecular Evolutionary Genetics Analysis Version 7.0 for Bigger Datasets. Available at: <https://pubmed.ncbi.nlm.nih.gov/27004904/> . Accessed on: February 01 ${ }^{\text {st }}, 2019$.

Li S, Peng Y, Zhu T, Zhu H, Mao C \& Qiao T (2012) Diversity of epiphytic fungi on the diseased and healthy leaves of Bambusa. African Jounal of Microbiology Research, 6:7556-7563.

Lin CS, Kalpana K, Chang WC \& Lin NS (2007) Improving multiple shoot proliferation in bamboo mosaic virus-free Bambusa oldhamii Munro propagation by liquid culture. HortScience, 42:1243-1246.

Liu JK, Phookamsak R, Doilom M, Wikee S, Li YM, Ariyawansha H, Boonmee S, Chomnunti P, Dai DQ, Bhat JD, Romero AI, Zhuang W, Monkai J, Jones EBG, Chukeatirote E, Ko TWK, Zhao Y, Wang Y \& Hyde KD (2012) Towards a natural classification of Botryosphaeriales. Fungal Diversity, 57:149-210.

Lu Y, Song S, Wang R, Liu Z, Meng J, Sweetman AJ, Jenkins A, Ferrier RC, Li H, Luo W, \& Wang T (2015) Impacts of soil and water pollution on food safety and health risks in China. Environment International, 77:05-15. 
Da Luz WC (1990) Microbiological control of bipolaris sorokiniana in vitro. Fitopatologia Brasileira, 15:246-247.

Manter DK \& Vivanco JM (2007) Use of the ITS primers, ITS1F and ITS4 to characterize fungal abundance and diversity in mixed-template samples by qPCR and length heterogeneity analysis. Jounal of Microbiology Methods, 71:07-14.

Martínez-Cano C, Grey W \& Sands DC (1992) First report of Arthrinium arundinis causing kernel blight on barley. Plant Disease, 76:1077.

Meletiadis J, Meis JFGM \& Mouton JW (2001) Analysis of Growth Characteristics of Filamentous Fungi in Different Nutrient Media. Jounal of Clinical Microbiology, 39:478-484.

Miao L, Kwong TFN \& Qian PY (2006) Effect of culture conditions on mycelial growth, antibacterial activity, and metabolite profiles of the marine-derived fungus Arthrinium c.f. saccharicola. Applied Microbiology and Biotechnology, 72:1063-1073.

Miura K \& Kudo MY (1970) An agar-medium for aquatic hyphomycetes. Transations of the Mycological Society of Japan, 11:116-118.

Mohanan C (1997) Diseases of bamboos in Asia: An illustrated manual. Beijing, INBAR. 228p.

Murashige T \& Skoog F (1962) A revised medium for rapid growth and bioassays with tobacco tissue cultures. Physiology Plant, $15: 473-497$.

Naznin H, Kiyohara D, Kimura M, Miyazawa M, Shimizu M \& Hyakumachi M (2014) Systemic resistance induced by volatile organic compounds emitted by plant growth-promoting fungi in Arabidopsis thaliana. PLoS One, 9:e86882.

Nei M \& Kumar S (2000) Molecular Evolution and Phylogenetics. Oxford, Oxford University Press. 328p.

Nisa H, Kamili AN, Nawchoo IA, Shafi S, Shameem N \& Bandh SA (2015) Fungal endophytes as prolific source of phytochemicals and other bioactive natural products: A review. Microbial Pathogenesis, 82:50-59.

Oses-Ruiz M, Sakulkoo W, Ittlejohn GR, Martin-Urdiroz M \& Talbot NJ (2017) Two independent S-phase checkpoints regulate appressorium-mediated plant infection by the rice blast fungus Magnaporthe oryzae. Proceedings of the National Academy of Sciences of the United States Of America, 114:E237-E244.

Oyetayo VO, Dong CH \& Yao YJ (2009) Antioxidant and Antimicrobial Properties of Aqueous Extract from Dictyophora indusiata. Open Mycology Journal, 3:20-26.

Pasqualini APA, Santos MC, Sant`Anna-Santos BF, Fraga HPF \& Quoirin M (2019) In vitro culture and diversity of endophytic fungi in Bambusa oldhamii. Pesquisa Agropecuária Tropical, 49:01-09.

Prabhu AS \& Filippi MC (2001) Graus de resistência à brusone e produtividade de cultivares melhoradas de arroz de terras altas. Pesquisa Agropecuária Brasileira, 36:1453-1459.

Prabhu AS, Filippi MC \& Castro N (1992) Pathogenic variation among isolates of Pyricularia oryzae affecting rice, wheat, and grasses in Brazil. Tropical Pest Management, 38:367-371.

Prabhu AS, Filippi MC, Silva GB, Lobo VLS \& Morais OP (2009) An Unprecedented Outbreak of Rice Blast on a Newly Released Cultivar BRS Colosso in Brazil. In: Wang GL \& Valent B (Eds.) Advances in Genetics, Genomics and Control Rice Blast Disease. New York, Springer. p. 257-266.

R Development Core Team (2017) R: A Language and environment for statistical computing. Vienna, R Foundation for Statistical Computing. Available at: <https://www.r-project.org/. Accessed on: July $01^{\text {st }}, 2018$
Rai M, Deshmukh P, Gade A, Ingle A, Kövics GJ \& Irinyi L (2009) Phoma saccardo: Distribution, secondary metabolite production and biotechnological applications. Critical Reviews in Microbiology, 35:182-196.

Ramos HP, Braun GH, Pupo MT \& Said S (2010) Antimicrobial activity from endophytic fungi Arthrinium state of Apiospora montagnei Sacc. and Papulaspora immersa. Brazilian Archives of Biology and Technology, 53:629-632.

Saitou N \& Nei M (1987) The neighbor-joining method: a new method for reconstructing phylogenetic trees. Molecular Biology and Evolution, 4:406-425.

Schulz B, Haas S, Junker C, Andrée N \& Schobert M (2015) Fungal endophytes are involved in multiple balanced antagonisms. Currunt Science, 109:39-45.

Selim KA, El-Beih AA, AbdEl-Rahman TM \& El-Diwany A (2012) Biology of Endophytic Fungi. Current Research in Environmental \& Applied Mycology, 2:31-82.

Sharma G \& Pandey RR (2010) Influence of culture media on growth, colony character and sporulation of fungi isolated from decaying vegetable wastes. Jounal of Yeast Fungal Reseach, $1: 157-164$.

Shen X, Zheng D, Gao J \& Hou C (2012) Isolation and evaluation of endophytic fungi with antimicrobial ability from Phyllostachys edulis. Bangladesh Jounal of Pharmacology, 7:249-257.

Shukla A, Singh A, Tiwari D \& Ahirwar BK (2016) Bambusicolous Fungi: A Reviewed Documentation. International Jounal of Pure \& Applied Bioscience, 4:304-310.

Silva HSA, Silva Romeiro R, Macagnan D, Almeida Halfeld-Vieira B, Pereira MCB \& Mounteer A (2004) Rhizobacterial induction of systemic resistance in tomato plants: Non-specific protection and increase in enzyme activities. Biological Control, 20:288295.

Sudha V, Govindaraj R, Baskar K, Al-Dhabi NA \& Duraipandiyan V (2016) Biological properties of Endophytic Fungi. Brazilian Archieves of Biology and Technology, 59:01-07.

Valenzuela-Lopez N, Cano-Lira JF, Guarro J, Sutton DA, Wiederhold N, Crous PW \& Stchigel AM (2018) Coelomycetous Dothideomycetes with emphasis on the families Cucurbitariaceae and Didymellaceae. Studies in Mycology, 90:01-69.

Wang J, Wei X, Qin X, Lin X, Zhou X, Liao S, Yang B, Liu J, Tu Z \& Liu Y (2015) Arthpyrones A-C, pyridone alkaloids from a sponge-derived fungus Arthrinium arundinis ZSDS1-F3. Organic Letters, 17:656-659.

White TJ, Bruns TD, Lee S \& Taylor JW (1990) Amplification of Direct Sequencing Fungal Ribosomal RNA Genes for Phylogenetics. In: Innis MA, Gelfand DH, Sninsky JJ \& White TJ (Eds.) PCR Protocols: A Guide to Methods and Applications. San Diego, Academic Press. p.315-322.

Wilson RA \& Talbot NJ (2009) Under pressure: Investigating the biology of plant infection by Magnaporthe oryzae. Nature Reviews Microbiology, 7:185-195.

Yan X \& Talbot NJ (2016) Investigating the cell biology of plant infection by the rice blast fungus Magnaporthe oryzae. Current Opinion in Microbiology, 34:147-153.

Zhang HW, Song YC \& Tan RX (2006) Biology and chemistry of endophytes. Natural Products Reports, 25:753-771.

Rev. Ceres, Viçosa, v. 67, n.4, p. 296-305, jul/aug, 2020 